\title{
Physicochemical Characterization of Artemether-Entrapped Solid Lipid Microparticles Prepared from Templated- Compritol and Capra hircus (Goat Fat) Homolipid
}

\author{
Petra Obioma Nnamani ${ }^{1,2,3}$, Franklin Chimaobi Kenechukwu ${ }^{1,}$, \\ Chinekwu Sheridan Nwagwu ${ }^{1}$, Onyinye Okoye ${ }^{1}$ and Anthony Amaechi Attama ${ }^{1}$
}

${ }^{1}$ Drug Delivery and Nanomedicine Research Group, Department of Pharmaceutics, Faculty of Pharmaceutical Sciences, University of Nigeria, Nsukka 410001, Enugu State, Nigeria

${ }^{2}$ Public Health \& Environmental Sustainability Research Group, Department of Pharmaceutics, Faculty of Pharmaceutical Sciences, University of Nigeria, Nsukka 410001, Enugu State, Nigeria ${ }^{3}$ Department of Drug Delivery, HIPS - Helmholtz Institute for Pharmaceutical Research Saarland, Saarbrücken, Germany

(Received: July 27, 2020, 2020; Accepted: May 22, 2021; Published (web): June 20, 2021)

\begin{abstract}
The purpose of this study was to formulate and evaluate the physicochemical properties of artemetherloaded solid lipid microparticles (SLM) prepared from templated-compritol $888^{\circledR}$ ATO and Capra hircus (goat fat) homolipid. Various ratios of compritol $888^{\circledR} \mathrm{ATO}$, goat fat and Phospholipon ${ }^{\circledR}$ 90G were used to prepare the templated lipid matrices and characterized by differential scanning calorimetry (DSC). Plain and artemether-loaded $\operatorname{SLM}(0,1.0,3.0$ and $5.0 \%$ drug) were prepared by melt-homogenization. The SLM were characterized regarding the compatibility by DSC, morphology and particle size by polarized light microscopy (PLM), encapsulation efficiency (EE\%), in vitro release in simulated gastric fluid (SGF, pH 1.2), simulated intestinal fluid (SIF, pH 7.2) and alcoholic buffer ( $\mathrm{pH}$ 3.6), and time-resolved $\mathrm{pH}$-dependent stability. Stable, smooth and mostly spherical SLM with particle sizes in the range $18.77-43.79 \mu \mathrm{m}$ and EE\% ranging from $62.22 \%$ to $99.05 \%$ were obtained. DSC results showed the compatibility of drug and the formulation excipients as well as the stability of artemether in the developed SLM. Results showed significantly $(\mathrm{p}<0.05)$ higher drug release $(88.25 \%)$ in alcoholic buffer than in SIF and SGF. By implication, incorporation of alcohol in the formulation would be a practical approach to improve artemether bioavailability from the SLM. This study has shown that the physicochemical properties of artemether were improved by SLM based on templated-compritol $888^{\circledR}$ ATO and goat fat.
\end{abstract}

Key words: Physicochemical characterization, compritol $888^{\circledR}$ ATO, artemether solid lipid microparticles (SLM), goat fat (Capra hircus), in vitro drug release, Phospholipon ${ }^{\circledR}$ 90G.

\section{INTRODUCTION}

Malaria is a life-threatening disease that continues to affect millions of people around the globe. ${ }^{1}$ It is caused by Plasmodium parasites transmitted by infected female Anopheles mosquitoes. The world health organization (WHO) has reported that the African region carries a disproportionately high share of the global malaria burden as $92 \%$ of the malaria cases are from this

Correspondence to: Franklin Chimaobi Kenechukwu, Tel: +234-8038362638. Fax:+234-42-771709;

E-mail: chimafrankduff@yahoo.com;

frankline.kenechukwu@unn.edu.ng

Dhaka Univ. J. Pharm. Sci. 20(1): 67-80, 2021 (June)

DOI: https://doi.org/10.3329/dujps.v20i1.54034 region, $85 \%$ of which are children under 5 years of age. ${ }^{1}$ Artemisinin and its derivatives are known to be the most effective antimalarial drugs and have been recommended by WHO as the first-line treatment for uncomplicated chloroquine-resistant malaria. In the treatment of malaria, one of the vital goals is to ensure a high drug concentration in the intracellular parasitophorous vacuoles hosting the plasmodium. ${ }^{2}$ However, there have been challenges with many antimalarial drugs which range from development of multi-drug resistance and non-specific localization to intracellular parasites which has brought about the need to use very high dose of these drugs that could 
cause some adverse effects in patients and consequently result to patient non-compliance. ${ }^{2,3} \mathrm{On}$ the other hand, artemether as well as other artemisinin-based anti-malarial drugs offer many advantages over other classes of anti-malarial, including the fact that they do not exhibit crossresistance to other drugs. ${ }^{4}$ It has also been elucidated that the endoperoxide moiety in these drugs have the ability to act on the erythrocytic stage of multi-drug resistant strains of Plasmodium falciparum and also clears the parasitemia more rapidly than other antimalarial drugs. ${ }^{3}$

Despite the advantages artemether offers in malaria therapy, it is a class IV drug according to the biopharmaceutics classification system (BCS), and as such poses the problem of poor aqueous solubility which could translate to low bioavailability. Over the years special drug delivery technologies have been employed to improve its solubility, one of which includes the use of lipid-based drug delivery systems. $^{4,5}$

Lipid-based drug delivery systems have been known to influence the absorption of active pharmaceutical ingredients via many mechanisms targeted at modifying the release of the active ingredients and as such improving bioavailability. ${ }^{5}$ Their proven safety as well as their ability to alter the intestinal environment in order to improve solubility of the active pharmaceutical ingredient (API) and also stimulate the lymphatic transport of the API have made them very suitable candidates for application in pharmaceutical formulations. Solid lipid microparticles are one of the commonly used lipid-based drug delivery systems in drug formulation and are made using solid lipid matrices, surfactants and water which have been known to improve the solubility of hydrophobic drugs. ${ }^{6-8}$ Their wide application in drug delivery might be due to the fact that they are physiologically compatible, costeffective and can easily be scaled up in production. ${ }^{9}$ This delivery system has also been known to prevent degradation of the active ingredient, provide sustained release as well as longer shelf-life. ${ }^{10}$
Previous studies have demonstrated favourable results using Capra hircus (goat fat)-based lipid matrices in formulating solid lipid microparticles (SLM) and solid lipid nanoparticles (SLN) formulations owing to the safety of goat fat and its outstanding qualities as a good solid lipid material. ${ }^{11-13}$ Compritol $880^{\circledR}$ ATO is one of the commonly used excipients in the formulation of SLM, SLN as well as nanostructured lipid carriers (NLC). Compritol-based lipid carriers have been successfully developed for various routes of drug administration including ocular, oral, topical, transdermal as well as rectal routes. ${ }^{14,15}$ This vast application stems primarily from the fact that it is not cytotoxic and provides high drug encapsulation efficiency: a feature brought about by the mono, di and tri-glycerides it contains which also helps in drug solubilisation. ${ }^{15}$ A study by Khatria et al demonstrated the efficiency of compritol-based artemether-loaded PEGylated SLN in the treatment of lung cancer. The study showed not only that the solubility of artemether was improved, but that the preparations brought about sustained release of the drug. ${ }^{16}$ To the best of our knowledge, there have been no reports of delivery of artemether using a lipid matrix made from a combination of compritol 888 ${ }^{\circledR}$ ATO and goat fat. In addition, although phospholipids have been employed to prepare artemether SLM by earlier researchers ${ }^{4}$, artemetherentrapped solid lipid microparticles prepared from templated - compritol $888{ }^{\circledR}$ ATO and goat fat have not been reported in the literature. Consequently, the aim of the work was to formulate artemether SLM from templated-compritol $888{ }^{\circledR}$ ATO and goat fat using hot homogenization method and evaluate the in vitro properties of such systems.

\section{MATERIALS AND METHODS}

Materials. The materials used in the study include artemether powder [JUHEL Pharmaceuticals Limited, Enugu State, Nigeria], ethanol, activated charcoal, bentonite, monobasic potassium phosphate, sodium hydroxide pellets and disodium hydrogen phosphate (BDH Chemicals Limited, Pooles, 
England), concentrated hydrochloric acid (SigmaAldrich, Germany), sorbitol, sorbic acid, goat fat, Compritol $\quad 888^{\circledR}$ ATO (Gattefossé, USA), Phospholipon ${ }^{\circledR}$ 90G (Phospholipid Köln, Germany).

Extraction and purification of goat fat. The wet rendering method was employed in the extraction of the lipid from goat fat. ${ }^{17,18}$ Briefly, extraneous materials were removed from the adipose tissues of the $C$. hircus, which were then cut into smaller pieces and subjected to moist heat by boiling in about half its weight of water on a water bath for $45 \mathrm{~min}$. The molten fat was separated from the aqueous phase by filtering with a muslin cloth and the extracted lipid purified using $2 \%$ suspension of activated charcoal and bentonite $(1: 19)$ at $80^{\circ} \mathrm{C}$ for $1 \mathrm{~h}$. The mixture was then filtered using a Buchner funnel. ${ }^{17,18}$

Preparation of lipid matrices. The lipid matrices employed in this study were first made from a combination of goat fat and Compritol $888^{\circledR}$ ATO in different rational ratios $(1: 1,1: 2,2: 1)$. The lipids were prepared by fusion method. ${ }^{19}$ Briefly, the lipids were melted in a crucible using a magnetic stirrer hot plate (SR1 UM 52188, Remi Equip., India) at $80{ }^{\circ} \mathrm{C}$, and stirred continuously until a homogenous melt was obtained. The mixture was then allowed to cool and solidify. Thereafter, each of the lipid matrices (70\%) was templated with Phospholipon ${ }^{\circledR}$ 90G (30 $\%$ ) following the above preparation technique to form templated lipid matrices, which were used for further formulation studies.
Formulation of solid lipid microparticles (SLM). The hot homogenization method was used ${ }^{19}$. Briefly, the lipid matrix was melted and maintained at a temperature of $80{ }^{\circ} \mathrm{C}$. Sorbitol, sorbic acid and Tween 80 were dispersed in aqueous continuous phase and maintained at the same temperature as the lipid matrix. The two phases were mixed and homogenized using the Ultra-Turrax (Silverson, UK) at a speed of 12,000 rpm for 5 mins. The drug-loaded SLM were prepared using the method explained above but the drug was dissolved in sufficient quantity of ethanol and dispersed in the lipid melt before emulsification. The formulation compositions of the SLM are depicted in Table 1.

\section{Characterization of lipid matrices and SLM}

Differential scanning calorimetry (DSC). Thermal properties of pure drug (artemether), compritol $888^{\circledR}$ ATO as well as the various formulations (lipid matrices and SLM) were determined using a differential scanning calorimeter (DSC 204F1 Netzch, Germany). Briefly, $5 \mathrm{mg}$ or 5 $\mathrm{ml}$ of sample was placed in an aluminum pan, hermetically sealed, and the thermal behaviour determined in the range of $35-190^{\circ} \mathrm{C}$ for unloaded samples and from $35^{\circ} \mathrm{C}$ to $400^{\circ} \mathrm{C}$ temperature range

Table 1. Formulation compositions of the solid lipid microparticles (SLM).

\begin{tabular}{lccccccc}
\hline Batches & $\begin{array}{c}\text { Ratio of compritol } \\
\text { to goat fat }(\mathrm{C}: \mathrm{G})\end{array}$ & $\begin{array}{c}\text { Lipid } \\
\text { matrix }(\mathrm{g})\end{array}$ & $\begin{array}{c}\text { Drug } \\
(\%)\end{array}$ & $\begin{array}{c}\text { Tween } 80 \\
(\mathrm{ml})\end{array}$ & $\begin{array}{c}\text { Sorbic acid } \\
(\mathrm{g})\end{array}$ & $\begin{array}{c}\text { Sorbitol } \\
(\mathrm{g})\end{array}$ & $\begin{array}{c}\text { Distilled } \\
\text { water }(\mathrm{ml})\end{array}$ \\
\hline $\mathrm{A} 1$ & $1: 1$ & 4 & 1 & 0.75 & 0.05 & 2 & 50 \\
$\mathrm{~A} 2$ & $1: 1$ & 4 & 3 & 0.75 & 0.05 & 2 & 50 \\
$\mathrm{~A} 3$ & $1: 1$ & 4 & 5 & 0.75 & 0.05 & 2 & 50 \\
B1 & $1: 2$ & 4 & 1 & 0.75 & 0.05 & 2 & 50 \\
B2 & $1: 2$ & 4 & 3 & 0.75 & 0.05 & 2 & 50 \\
B3 & $1: 2$ & 4 & 5 & 0.75 & 0.05 & 2 & 50 \\
C1 & $2: 1$ & 4 & 1 & 0.75 & 0.05 & 2 & 50 \\
C2 & $2: 1$ & 4 & 3 & 0.75 & 0.05 & 2 & 50 \\
C3 & $2: 1$ & 4 & 5 & 0.75 & 0.05 & 2 & 50 \\
A0 & $1: 1$ & 4 & 0 & 0.75 & 0.05 & 2 & 50 \\
B0 & $1: 2$ & 4 & 0 & 0.75 & 0.05 & 2 & 50 \\
C0 & $2: 1$ & 4 & 0 & 0.75 & 0.05 & 2 & 50 \\
\hline
\end{tabular}


for drug-loaded samples under a $20 \mathrm{ml} / \mathrm{min}$ nitrogen flux at a heating rate of $10^{\circ} \mathrm{C} / \mathrm{min}$. The baselines were determined using an empty pan, and all the thermograms were baseline corrected. ${ }^{20}$

Morphology and particle size analysis. A specified quantity of sample from each batch was placed on a glass slide and viewed with a photomicroscope (Hund $^{\circledR}$, Weltzlar, Germany) attached with an electronic image analyzer (Moticam, Xiamen, China) at a magnification of 100 times. The size of particles of the SLM from each batch were measured ( $\mathrm{n}=100)$, and the mean value was determined. The morphologies were also observed from the photomicrographs.

Drug encapsulation efficiency. A $5 \mathrm{ml}$ quantity of each of the SLM dispersion was centrifuged at $3000 \mathrm{rpm}$ for $40 \mathrm{~min}$ and the supernatant assayed with a UV-VIS spectrophotometer (Spectrum lab $752 \mathrm{~s}, \mathrm{UK}$ ) at predetermined wavelength of $310 \mathrm{~nm}$ and the amount of drug encapsulated was calculated with reference to the Beer's plot using the formula;

$$
E E(\%)=\frac{\text { Calulated drug content }}{\text { Theoretical drug content }} \times \frac{100}{1} \quad 1
$$

In vitro drug release studies. The release of artemether from the various batches of SLM was evaluated using $900 \mathrm{ml}$ of alcoholic buffer ( $\mathrm{pH}$ 3.6), simulated gastric fluid without enzymes ( $\mathrm{pH} 1.2)$, and simulated intestinal fluid without enzymes ( $\mathrm{pH} 7.2)$ respectively, maintained at $37 \pm 1^{\circ} \mathrm{C}$ and $50 \mathrm{rpm}$. Prior to the commencement of the study, the dialysis membrane (MWCO 6000-8000, Spectra Labs, Breda, Netherlands) was soaked in each of the media for 24 h. A quantity of the SLM equivalent to $50 \mathrm{mg}$ of artemether was weighed and placed in the dialysis membrane containing about $2 \mathrm{ml}$ of the medium and tied properly with a heat-resistant thread and placed in the medium. A $5 \mathrm{ml}$ volume of the dissolution medium was withdrawn at predetermined time intervals, diluted and the drug content analyzed using a UV-VIS spectrophotometer (Spectrum lab 752s, UK). A $5 \mathrm{ml}$ volume of fresh medium was used to replace the withdrawn quantity in order to maintain sink condition.
In vitro release kinetics. The release profiles of the various SLM batches in SGF, SIF, as well as in alcoholic buffer were analyzed to determine the in vitro release kinetic mechanism using four models: zero order equation, First-order equation, Higuchi square root model and Korsmeyer-Peppas empirical model as shown in equations 2-5, respectively.

$\begin{array}{ll}\mathrm{Q}=\mathrm{K}_{1} \mathrm{t} & 2 \\ \mathrm{Q}=100\left(1-\mathrm{e}^{\mathrm{k} 2 \mathrm{t}}\right) & 3 \\ \mathrm{Q}=\mathrm{K}_{3}(\mathrm{t})^{1 / 2} & 4 \\ \frac{M t}{M \alpha}=\mathrm{Kt}^{\mathrm{n}} & 5\end{array}$

where $\mathrm{Q}$ is the amount of drug released at time $\mathrm{t}$, $\mathrm{Mt} / \mathrm{M}$ is the fraction of drug released at time $t, n$ is diffusion exponent indicative of the mechanism of transport of drug through the polymer, $\mathrm{K}_{1}, \mathrm{~K}_{2}, \mathrm{~K}_{3}$ and $\mathrm{K}$ are the rate constants of zero-order, First-order, Higuchi and Korsmeyer-Peppas models, respectively.

Time-dependent $\mathbf{p H}$ stability studies. The $\mathrm{pH}$ of dispersions of the SLM were determined over time (at $24 \mathrm{~h}, 1$ week and 1 month), using a $\mathrm{pH}$ meter (pH $\mathrm{ep}^{\circledR}$ Hanna instrument, Padova, Italy).

Statistical analysis. All experiments were performed in replicates (at least $n=3$ ) for validity of statistical analysis. Results were expressed as mean \pm SD. ANOVA and student t-tests were performed on the data sets generated using SPSS. Differences were considered significant for $\mathrm{P}$ values $<0.05$

\section{RESULTS AND DISCUSSION}

DSC analysis. The thermal properties of the formulations are shown in Figures 1 and 2. The DSC thermogram of goat fat showed an endothermic peak at $53.7^{\circ} \mathrm{C}$ with an enthalpy of $-5.067 \mathrm{~mW} / \mathrm{mg}$ while that of compritol $880^{\circledR}$ ATO showed a sharp endothermic single peak corresponding to melting at $75.2{ }^{\circ} \mathrm{C}$ with enthalpy of $-14.94 \mathrm{~mW} / \mathrm{mg}$, confirming the purity of the compritol $888^{\circledR}$ ATO (Table 2). The thermogram of Phospholipon ${ }^{\circledR}$ 90G (P90G) showed a sharp endothermic single peak corresponding to melting at $232^{\circ} \mathrm{C}$, and crystallizes partially at $327.9^{\circ} \mathrm{C}$ (Figure 1). The DSC thermogram of pure artemether 
showed an endothermic peak at $89.6^{\circ} \mathrm{C}$ with enthalpy of $-19.38 \mathrm{~mW} / \mathrm{mg}$ and an exothermic peak at $180{ }^{\circ} \mathrm{C}$ with enthalpy of $24 \mathrm{~mW} / \mathrm{mg}$ (Figure 1). The DSC thermograms of binary mixtures of compritol $880^{\circledR}$ ATO and goat fat matrices showed sharp endothermic single melting peaks of $71.73^{\circ} \mathrm{C}$ and $74.8^{\circ} \mathrm{C}$ respectively for the $1: 1$ and $2: 1$ lipid matrices, with corresponding enthalpies of - 30.51 and -22.78 $\mathrm{mW} / \mathrm{mg}$. The 1:2 lipid matrix however showed a sharp endothermic single peak corresponding to melting at $49.6^{\circ} \mathrm{C}$ and crystallizes partially at $65.8^{\circ} \mathrm{C}$, with enthalpies of - 20.04 and - $19.5 \mathrm{~mW} / \mathrm{mg}$, respectively (Figure 2). The drug-loaded lipid matrices generally showed peaks with low enthalpies

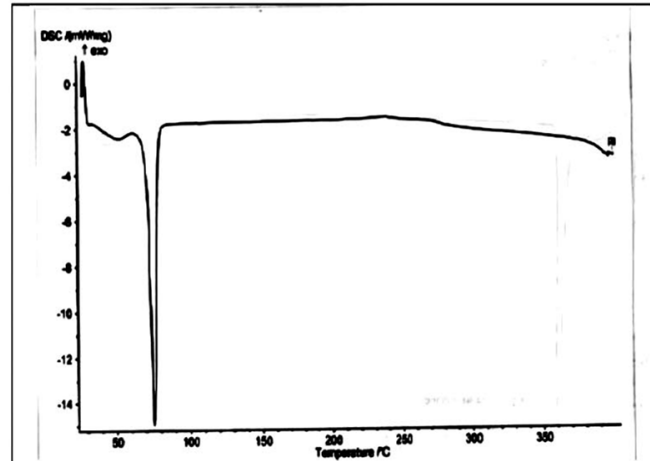

a

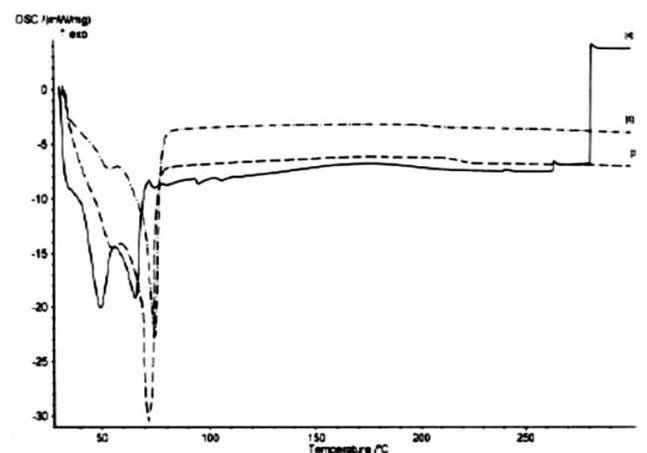

c

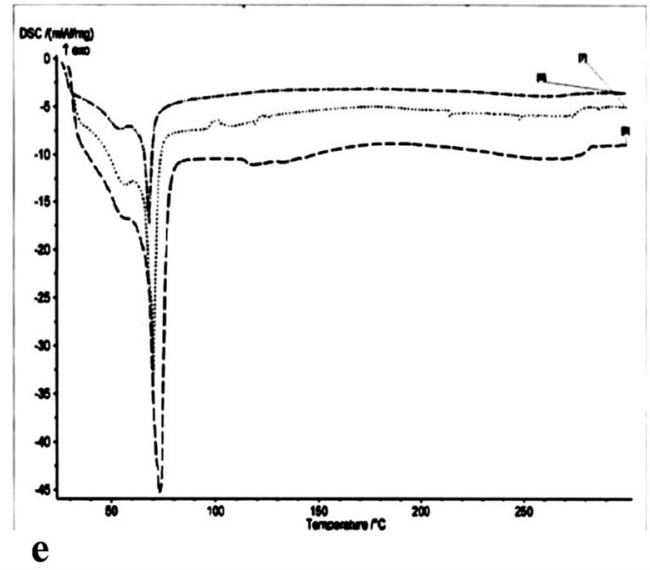

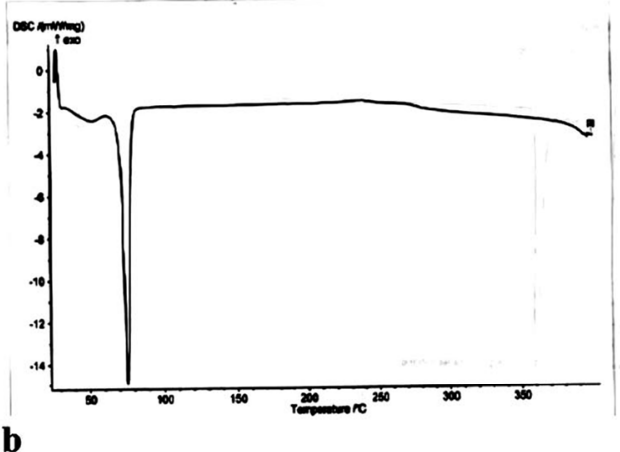

b

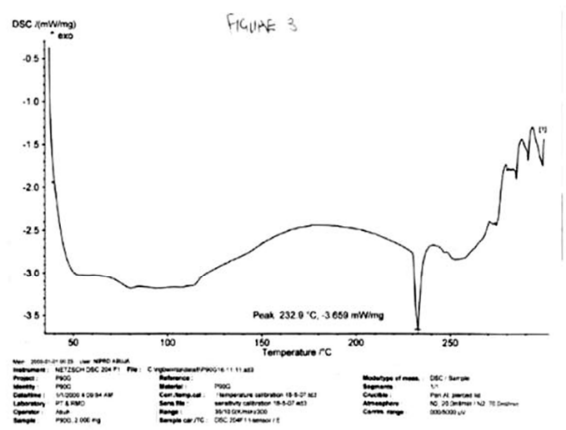

d

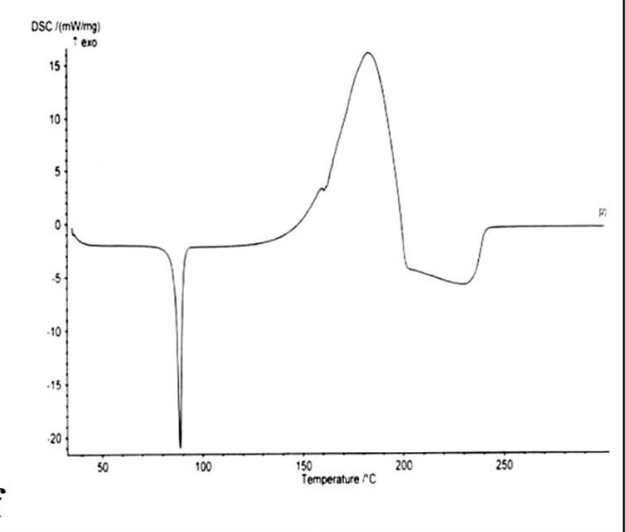

Figure 1. DSC thermograms of (a) goat fat, (b) compritol $888^{\circledR}$ ATO, (c) lipid matrices based on goat fat and compritol $888^{\circledR}$ ATO in superposition, (d) Phospholipon ${ }^{\circledR}$ 90G, (e) Phospholipon ${ }^{\circledR}$ 90G templated-compritol $888{ }^{\circledR}$ ATO and goat fat lipid matrices in superposition, (f) pure artemether sample. 

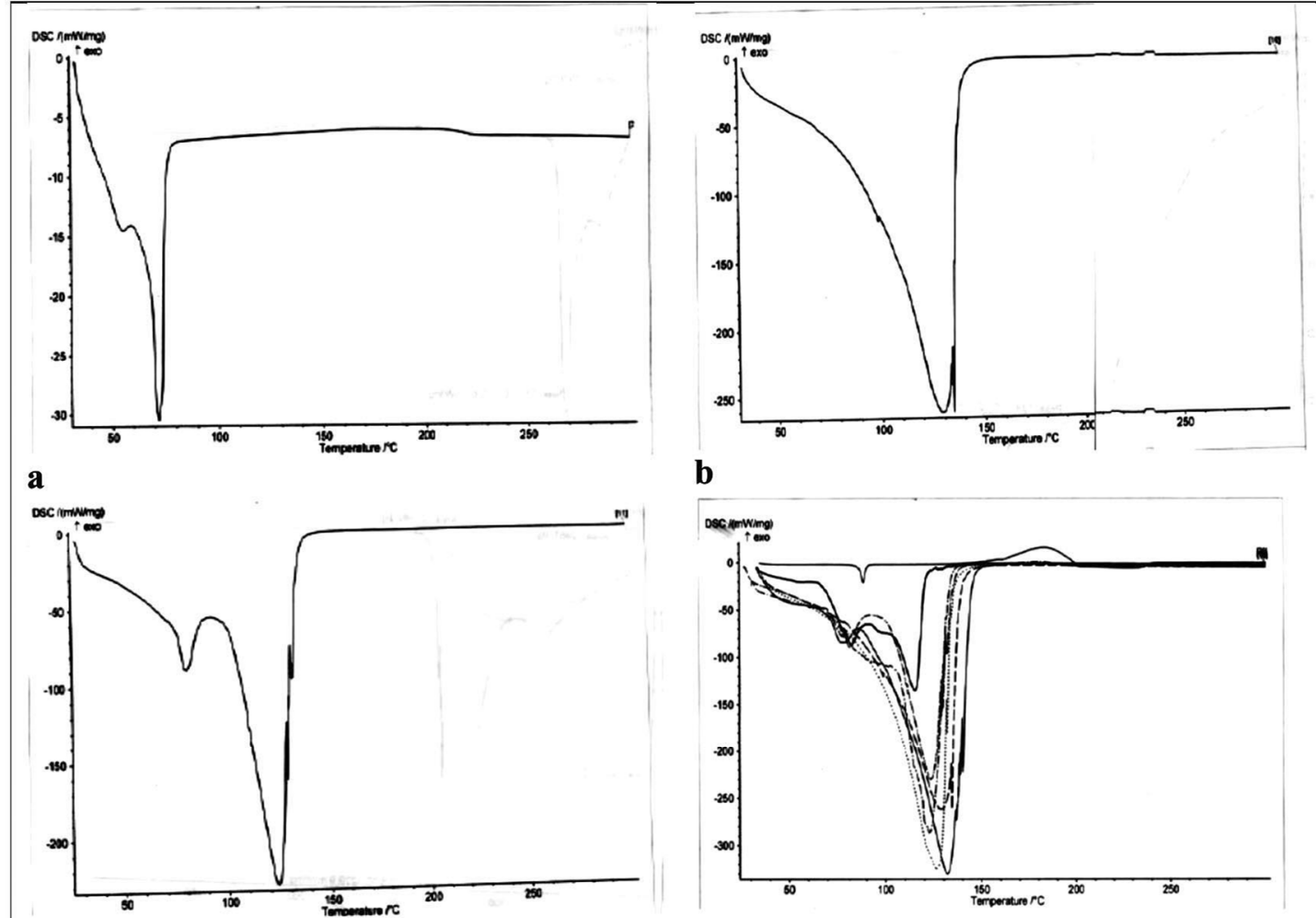

b

c

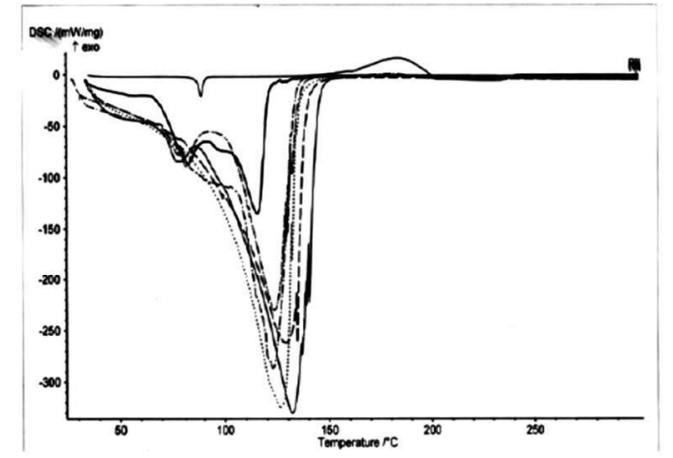

d

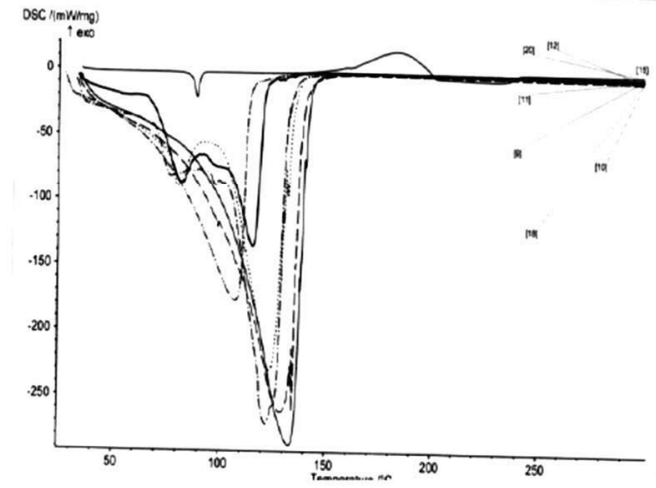

e

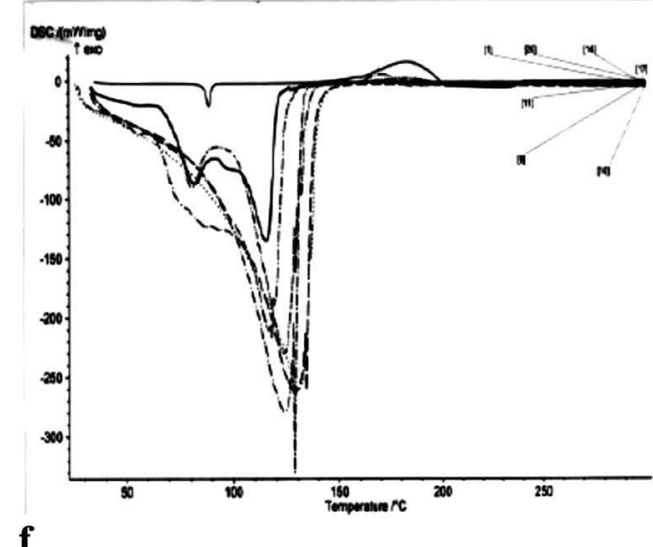

Figure 2. DSC thermogram of (a) unloaded SLMs prepared with (1:1) templated lipid matrix, (b) unloaded SLMs prepared with (1:2) templated lipid matrix, (c) unloaded SLMs prepared with (2:1) templated lipid matrix, (d) 1\% artemether-loaded SLMs prepared with templated lipid matrices in superposition, (e) 3\% artemether-loaded SLMs prepared with templated lipid matrices in superposition, (f) $5 \%$ artemether-loaded SLMs prepared with templated lipid matrices in superposition.

according to the drug concentration and lipid content. The results of the thermal analysis showed that the goat fat used in the study had a melting point value slightly different from that in the literature. This difference may possibly be due to variation in the sensitivity of the DSC machines used or due to the fact that this preparation utilized distilled water instead of bi-distilled water ${ }^{21}$. On the other hand, the thermogram of Phospholipon ${ }^{\circledR}$ 90G showed a sharp endothermic single peak corresponding to melting at $232^{\circ} \mathrm{C}$, and partial crystallization at $327.9^{\circ} \mathrm{C}$, confirming the purity of $\mathrm{P} 90 \mathrm{G}$ and that its melting is instantaneous at a high temperature. It also shows that P90G has the tendency of undergoing rapid 
crystallization with increased temperature. The DSC thermogram of pure artemether showed an endothermic peak at $89.6^{\circ} \mathrm{C}$ with enthalpy of -19.38 $\mathrm{mW} / \mathrm{mg}$ and an exothermic peak at $180^{\circ} \mathrm{C}$ with enthalpy of $24 \mathrm{~mW} / \mathrm{mg}$. This indicates the purity of the drug and due to the decomposition it underwent during melting, and the decomposed portion gave the pseudo - melting peak $\left(183.2^{\circ} \mathrm{C}\right)$. The result also strongly suggests that the drug was stable throughout

Table 2. Drug release kinetics of the solid lipid microparticles formulations in various release media.

\begin{tabular}{|c|c|c|c|c|c|c|}
\hline \multirow{2}{*}{$\begin{array}{l}\text { Release } \\
\text { medium }\end{array}$} & \multirow[t]{2}{*}{ Batch code } & \multirow{2}{*}{$\begin{array}{c}\text { Zero order } \\
\left(\mathrm{R}^{2}\right)\end{array}$} & \multirow{2}{*}{$\begin{array}{c}\text { First order } \\
\left(\mathrm{R}^{2}\right)\end{array}$} & \multirow{2}{*}{$\begin{array}{l}\text { Higuchi } \\
\left(\mathrm{R}^{2}\right)\end{array}$} & \multicolumn{2}{|c|}{ Kosmeyer-peppas } \\
\hline & & & & & $\left(\mathrm{R}^{2}\right)$ & $\mathrm{N}$ \\
\hline \multirow{10}{*}{$\begin{array}{l}\text { Alcoholic } \\
\text { buffer }\end{array}$} & A1 & 0.7007 & 0.9556 & 0.9631 & 0.9633 & 0.487 \\
\hline & A3 & 0.9227 & 0.9497 & 0.9056 & 0.9554 & 0.749 \\
\hline & A5 & 0.7494 & 0.9484 & 0.9900 & 0.9901 & 0.493 \\
\hline & B1 & 0.8035 & 0.9736 & 0.9768 & 0.9792 & 0.542 \\
\hline & B3 & 0.7241 & 0.9533 & 0.9820 & 0.9826 & 0.481 \\
\hline & B5 & 0.7504 & 0.9335 & 0.9740 & 0.9740 & 0.497 \\
\hline & $\mathrm{C} 1$ & 0.9076 & 0.9495 & 0.9189 & 0.9556 & 0.705 \\
\hline & $\mathrm{C} 3$ & 0.8350 & 0.9729 & 0.9728 & 0.9791 & 0.567 \\
\hline & $\mathrm{C} 5$ & 0.8373 & 0.9742 & 0.9744 & 0.9808 & 0.572 \\
\hline & Commercial sample & 0.4412 & 0.9866 & 0.9321 & 0.9669 & 0.375 \\
\hline \multirow[t]{10}{*}{ SGF } & A1 & 0.6233 & 0.8583 & 0.9376 & 0.9406 & 0.458 \\
\hline & A3 & 0.6857 & 0.9088 & 0.9346 & 0.9346 & 0.496 \\
\hline & A5 & 0.6128 & 0.9038 & 0.9637 & 0.9710 & 0.437 \\
\hline & B1 & 0.6687 & 0.9269 & 0.9654 & 0.9673 & 0.467 \\
\hline & B3 & 0.7532 & 0.9345 & 0.9599 & 0.9602 & 0.515 \\
\hline & B5 & 0.4357 & 0.8431 & 0.9221 & 0.9579 & 0.373 \\
\hline & $\mathrm{C} 1$ & 0.8949 & 0.9759 & 0.9673 & 0.9860 & 0.633 \\
\hline & $\mathrm{C} 3$ & 0.8647 & 0.9643 & 0.9813 & 0.9903 & 0.587 \\
\hline & $\mathrm{C} 5$ & 0.5371 & 0.8785 & 0.9569 & 0.9751 & 0.406 \\
\hline & Commercial sample & -0.0146 & 0.7551 & 0.7538 & 0.8990 & 0.279 \\
\hline \multirow[t]{10}{*}{ SIF } & A1 & 0.8412 & 0.9443 & 0.9419 & 0.9557 & 0.608 \\
\hline & A3 & 0.8500 & 0.9617 & 0.9350 & 0.9526 & 0.625 \\
\hline & A5 & 0.8621 & 0.9654 & 0.9358 & 0.9556 & 0.634 \\
\hline & B1 & 0.9024 & 0.9691 & 0.9094 & 0.9516 & 0.714 \\
\hline & B3 & 0.7371 & 0.9330 & 0.9448 & 0.9456 & 0.523 \\
\hline & B5 & 0.6150 & 0.8907 & 0.9433 & 0.9477 & 0.451 \\
\hline & $\mathrm{C} 1$ & 0.7869 & 0.8945 & 0.9040 & 0.9143 & 0.593 \\
\hline & $\mathrm{C} 3$ & 0.8648 & 0.9635 & 0.9316 & 0.9536 & 0.642 \\
\hline & $\mathrm{C} 5$ & 0.7991 & 0.9572 & 0.9441 & 0.9504 & 0.570 \\
\hline & Commercial sample & 0.0209 & 0.8424 & 0.7397 & 0.8639 & 0.289 \\
\hline
\end{tabular}

the duration of the study. It was also observed that the structuring of the compritol $880^{\circledR}$ ATO- goat fat lipid matrices with $\mathrm{P} 90 \mathrm{G}$ also produced matrices with lower melting endotherms as well as enthalpies, which suggests less crystallinity of lipid matrices. ${ }^{20,21}$
The P90G is a good surface modifier for solid lipid microparticles, with resultant improvement in targeting and pharmacokinetics. ${ }^{22-24}$ The phospholipid bilayer structure formed around the lipid core may increase the drug loading capacity, as biologically 
important molecules can attach to the colloidal particle surface, and surface modification also enables stabilization of colloidal particles especially when generation of the microparticles is carried out in aqueous medium. ${ }^{25}$ Furthermore, P90G used in this study mainly contains linoleic, oleic, stearic and palmitic acids, which are fatty acids of different chain lengths and degrees of unsaturation. ${ }^{24}$ The interaction of these fatty acids with the diverse fatty acids present in goat fat and compritol $880^{\circledR}$ ATO may have resulted in the partly amorphous nature of the lipid matrix containing the phospholipid, consistent with earlier studies. ${ }^{26-29}$ It was also observed that the drug-loaded lipid matrices showed peaks with low enthalpies according to the drug concentration and lipid content which strongly indicates high drug loading as well as uniform distribution of the drug in the lipid matrix.
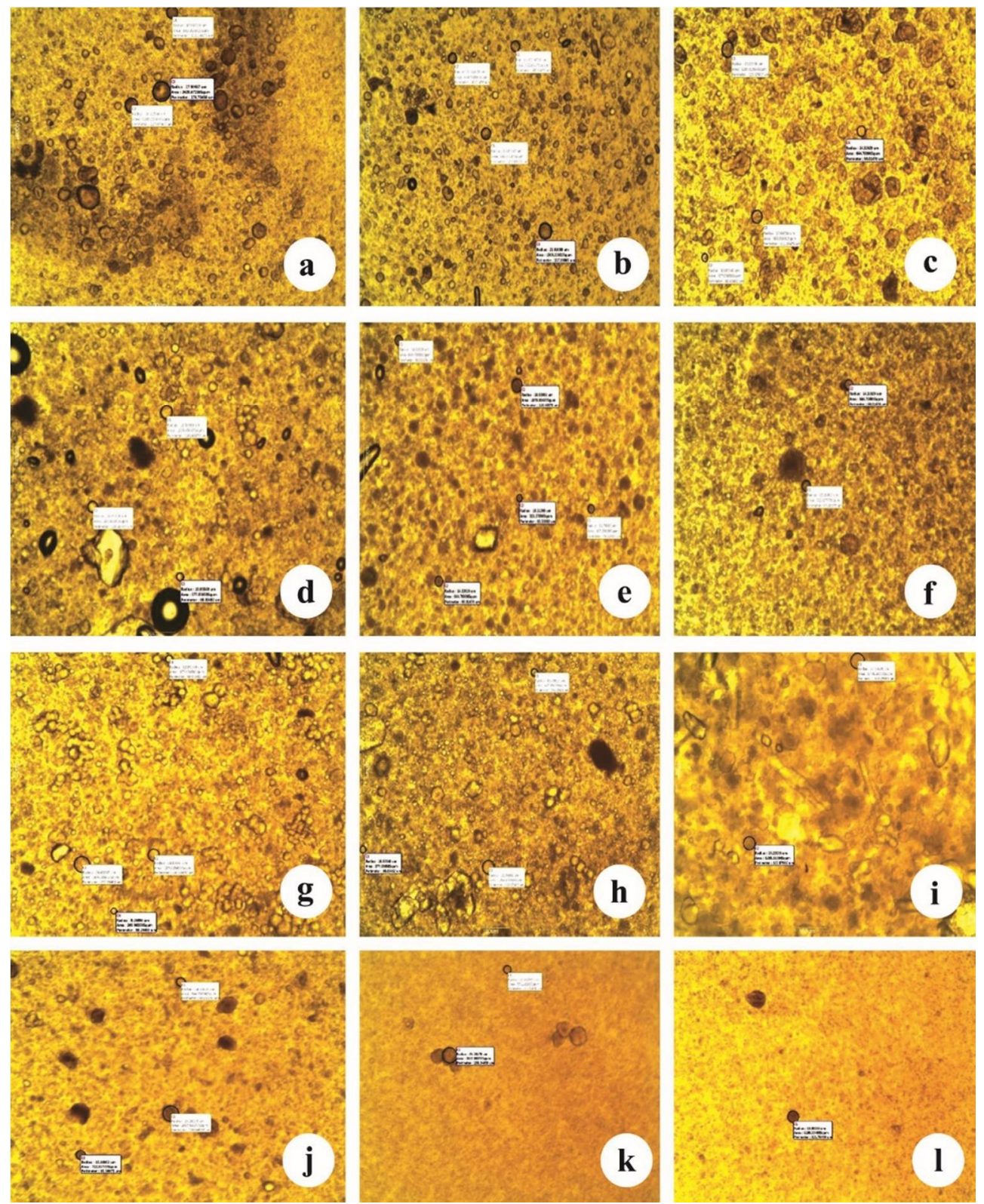

Figure 3. Photomicrograph of $1 \%$ artemether-loaded SLM formulations (a-c), 3\% artemether-loaded SLM formulations (d-f), 5\% artemether-loaded SLM formulations (g-i) and unloaded SLM formulations (j-1). Key: a-c represents batches A1-C1 respectively; d-f represents batches A2-C2 respectively; g-I represents batches A3-B3, respectively; while j-1 represents batches A0-C0, respectively. 
Physicochemical properties of SLM. The mean particle size analysis as well as the morphological assessment of the various SLM formulations were performed using optical microscopy and the results are depicted in Figure 3. The average particle size of the microparticles $(n=100)$ was in the range of 18.77$43.79 \mu \mathrm{m}$. Batch B0 had the smallest average particle size $(18.77 \mu \mathrm{m})$ while batch C3 had the largest particle size $(43.79 \mu \mathrm{m})$. The photomicrograph for the unloaded SLM batches (A0, B0 and C0) showed smooth and well-formed microparticles which were mostly spherical in shape. On the other hand, the drug-loaded batches showed particles with a combination of spherical and irregular appearances.

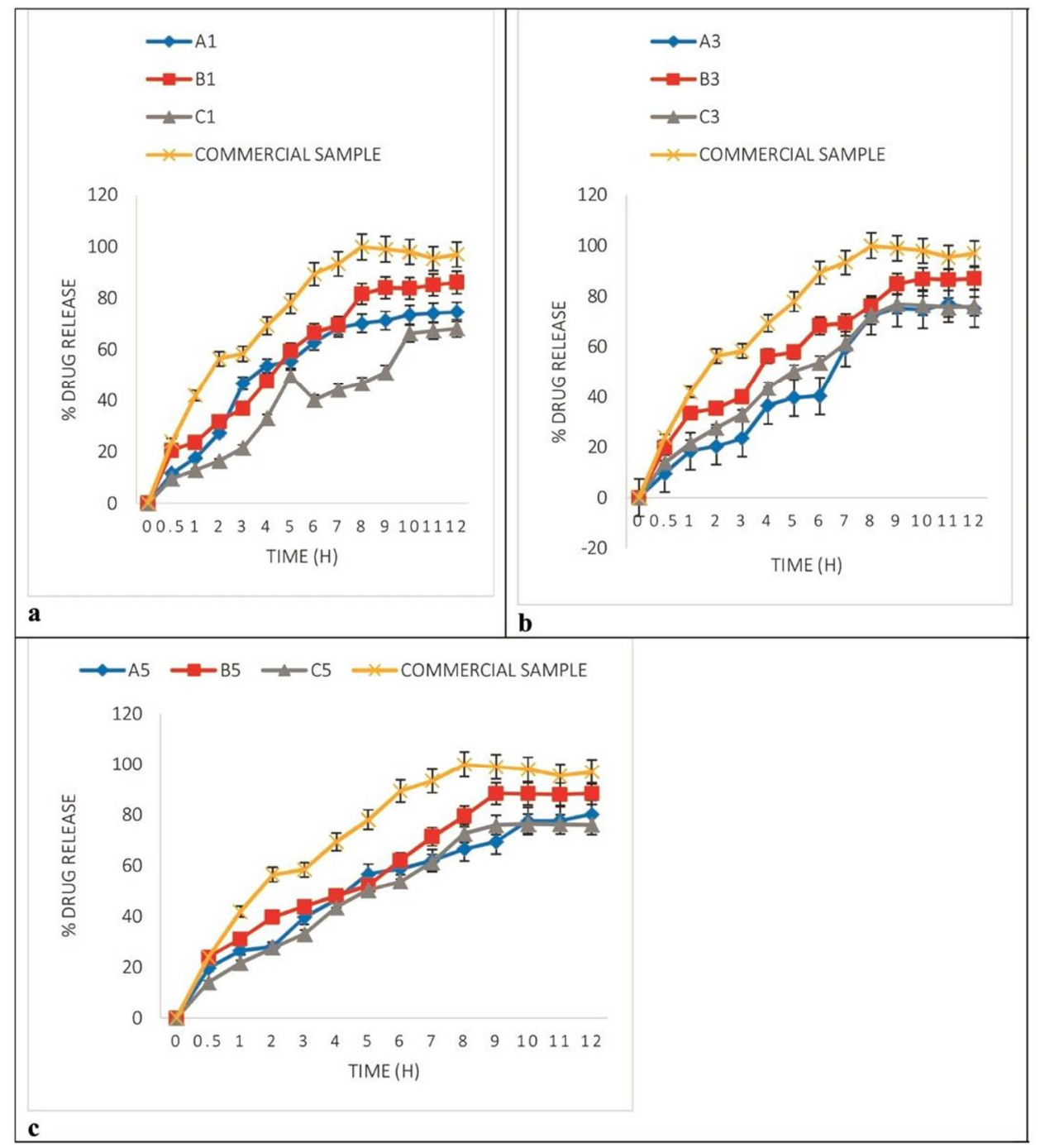

Figure 4. In vitro drug release in alcoholic buffer from SLMs formulation containing (a) $1 \%$ artemether (b) $3.0 \%$ artemether and (c) $5.0 \%$ artemether.

Particle size characterization of SLM is essential in ensuring the production of a stable and quality product. It is vital to point out that particle size plays a vital role in the physical stability of SLM. ${ }^{30}$ The size distribution is affected by wide range of factors including temperature, polymer/lipid concentration as well as viscosity of the continuous phase. ${ }^{31}$ The average particle size was in the range of 18.77-43.79 $\mu \mathrm{m}$ and this variation might be as a result of variations in the lipid matrix composition. ${ }^{4}$ Also, the 
mean particle sizes of the unloaded batches were found to be smaller compared to the drug-loaded batches implying that the process of drug loading produced significant $(\mathrm{p}<0.05)$ increase in the particle size due to increase in the concentration of drug encapsulated in the matrix as previously reported. ${ }^{29,32}$
This might also be due to the fact that a decrease in the volume of the continuous phase brought about an increase in drug concentration. This can result to increase in the viscosity of the system which in turn would require more energy to breakdown the droplets of the disperse phase. ${ }^{33}$

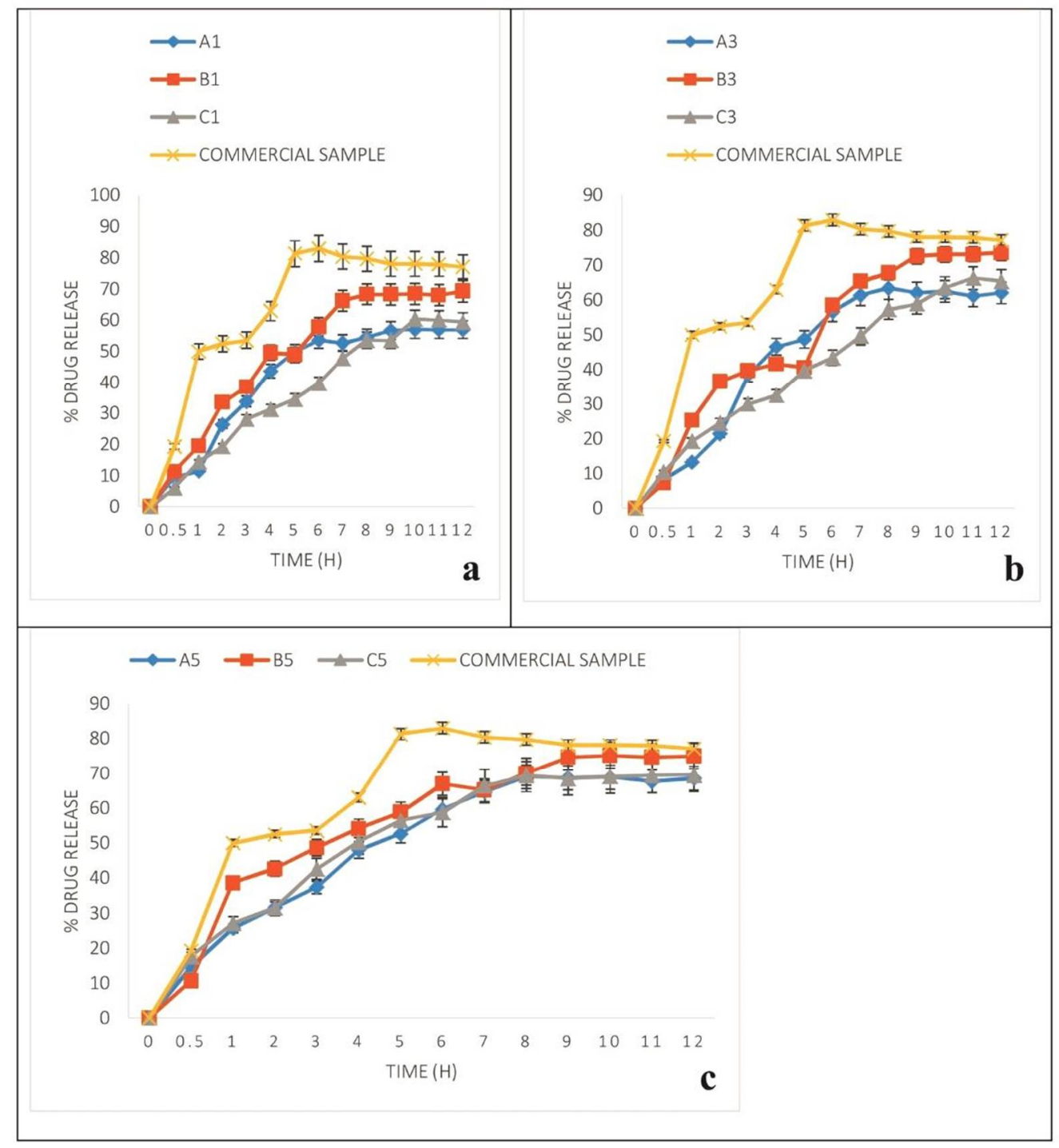

Figure 5. In vitro drug release in SGF from the SLMs formulation containing (a) $1 \%$ artemether (b) $3.0 \%$ artemether and (c) $5.0 \%$ artemether.

The drug encapsulation efficiency was evaluated using spectrophotometric method and the EE\% of the SLM was in the range of $62.22-99.05 \%$, with batch C3 having the highest EE (99.05\%). Batch C1 showed the lowest EE\% and this might be due to the fact that it had the smallest mean particle size. ${ }^{33}$ It was also observed that increase in the drug concentration for the various batches brought about a corresponding increase in the EE\% implying that the lipid matrix promoted concentration dependent encapsulation. ${ }^{34}$ 
In vitro drug release. The in vitro release study of the artemether-loaded SLM and the commercially available product was performed in alcoholic buffer, simulated gastric fluid (SGF) and simulated intestinal fluid (SIF) and the results represented in Figures 4-6. The results showed that there was a very significant $(\mathrm{p}<0.05)$ release of artemether from the various batches of formulation in all the media used. However, the in vitro drug release carried out revealed that $100 \%$ drug release at the end of $12 \mathrm{~h}$ was not attained in all the media used in this study. It

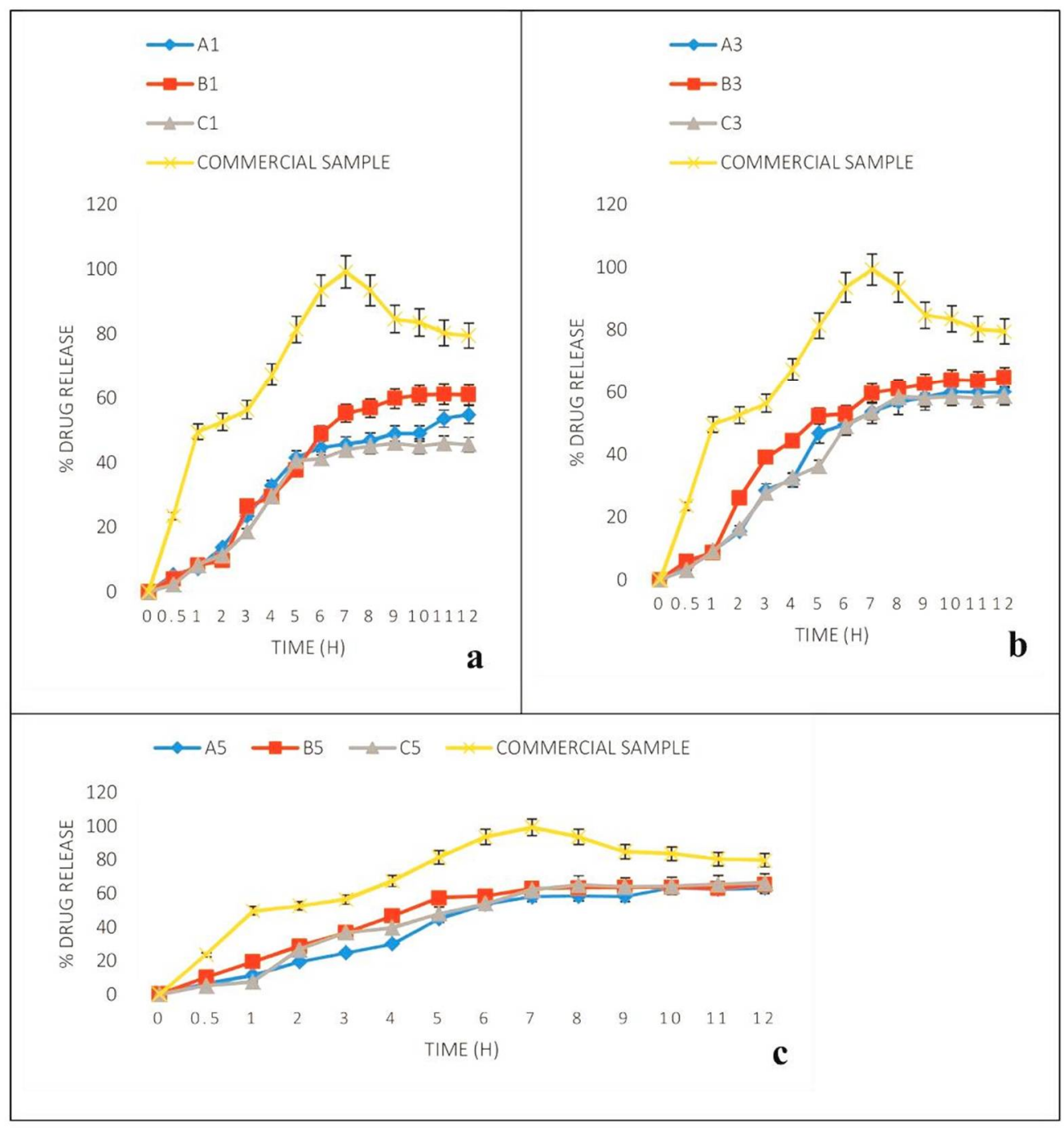

Figure 6. In vitro drug release in SIF from the SLM formulation containing (a) $1 \%$ artemether (b) $3.0 \%$ artemether and (c) $5.0 \%$ artemether.

was also observed that all the batches showed significantly $(\mathrm{p}<0.05)$ higher release rate in alcoholic buffer when compared with their various release rates in SGF and SIF. This strongly suggests that the dissolution of artemether may be improved by the presence of alcohol. The commercial sample was found to produce significantly $(\mathrm{p}<0.05)$ higher release rate than the formulation batches in all the media used for the study. It was also observed that 9.48-23.82\% drug release occurred within $30 \mathrm{~min}$ strongly indicating a burst effect. This might also suggest the presence of a significant amount of the drug present on the surface of the SLM ${ }^{4}$. In SGF, batch B5 had the highest percentage drug release 
(74.88\%) while batch A1 had the lowest release after $12 \mathrm{~h}$. In SIF, however, batch C5 was seen to exhibit the highest percentage drug release while batch $\mathrm{C} 1$ had the lowest (45.5\%). It was also observed that the highest percentage drug release $(88.25 \%)$ occurred in alcoholic buffer follwed by SGF and then SIF.

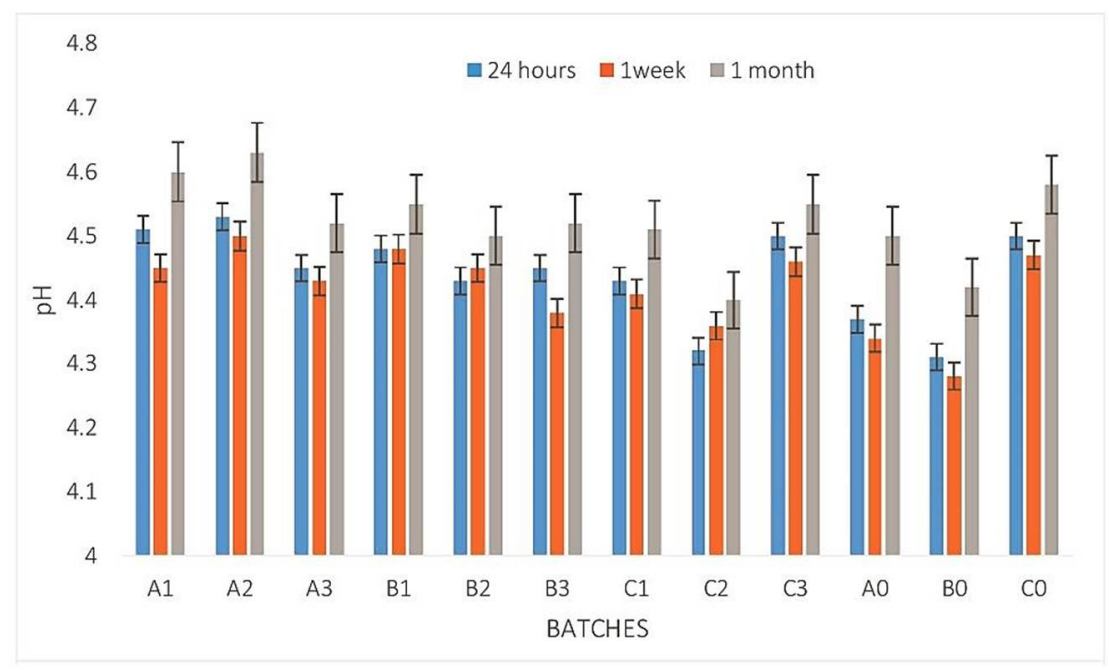

Figure 7. Time-dependent $\mathrm{pH}$ stability studies.

In vitro release kinetics. Four mathematical models were employed to analyze the kinetics as well as the release mechanism of artemether from the SLM formulations and the data obtained is shown in Table 2. It was observed that the release of artemether from the various batches of formulation in SIF, SGF and alcoholic buffer followed a mixed first order and Higuchi release patterns. The mechanism of release of artemether from the lipid matrix in alcoholic buffer and SIF was by non-fickian diffusion and erosion. In SGF, the mechanism for batches A5, B5 and C5 was by fickian diffusion while the rest of the batches was by non fickian diffusion and erosion.

On evaluation, it was observed that the release of artemether from the various batches of formulation in SIF, SGF and alcoholic buffer followed a mixed first order and Higuchi release patterns as seen in Table 2, which implies that the release of artemether in the media was dependent on the concentration of the dissolved drug in the system. This has been reported to be the case in situations where the drug is soluble in the medium used for the analysis. ${ }^{35,36}$ The analysis using Kosmeyer-Peppas model in alcoholic buffer and SIF showed that all the SLM formulations had "n" values greater than 0.45 , which suggests that the mechanism of drug release was by non-fickian diffusion. It also indicates that artemether was released from the matrix by the process of diffusion as well as erosion. ${ }^{36}$ However in SGF, batches A5, B5 and C5 unlike the other batches had " $n$ " values less than $0.45(0.437,0.373$ and 0.406 respectively), which suggests a fickian diffusion release mechanism. This was also the case for the commercial sample in all the media as they had " $n$ " values less than 0.45 as well.

Time-dependent pH stability. The $\mathrm{pH}$ stability of the formulations stored at room temperature was evaluated at various time interval. The result of the study is shown in Figure 7. In general, there was no significant $(\mathrm{p}<0.05)$ change in the $\mathrm{pH}$ of the batches over the period of one month. After $24 \mathrm{~h}$, the SLM batches had $\mathrm{pH}$ values in the range of 4.31-4.53. On evaluation after 1 week, all the batches with the exception of B1, B2 and $\mathrm{C} 2$ batches, experienced a slight reduction in $\mathrm{pH}$ with values in the range of 4.28-4.47. Batch $\mathrm{B} 1$ showed no change in $\mathrm{pH}$ after 1 week. On the other hand, batches B2 and C2 showed a very slight increase in $\mathrm{pH}$ after 1 week. After one month, the $\mathrm{pH}$ values for all the batches increased with values in the range of 4.40-4.63. 
The $\mathrm{pH}$ of maximum stability of a drug is a vital tool in the design as well as formulation of a stable delivery system as it can inform the formulation scientist on the necessity of a stabilizer in the formulation. ${ }^{4}$ The $\mathrm{pH}$ of the various formulation batches as seen in Figure 7 was in the acidic region after $24 \mathrm{~h}$ of formulation and even after 1 month of storage. The $\mathrm{pH}$ of the unloaded SLM were also in the acidic region as those of the drug-loaded SLM implying that the acidity may be due to the fatty acid content of the lipid matrix and not as a result of drugloading. ${ }^{4}$ The variation in $\mathrm{pH}$ over time, however slight, might be indicative of a possible degradation on further storage hence the need for the incorporation of a buffer in these formulations.

\section{CONCLUSIONS}

Artemether-loaded SLM were developed using compritol $888{ }^{\circledR}$ ATO and goat fat-based lipid matrices by hot homogenization method. The study showed that the technique employed was very effective in formulating SLM. The high EE\% achieved with the matrices suggests that the SLM could represent an effective way of delivering hydrophobic active ingredients. Although the in vitro release study showed that commercial sample had the highest percentage drug release, an in vivo evaluation could be carried out to further ascertain the characteristics of these formulations in vivo. Results showed significantly $(\mathrm{p}<0.05)$ higher drug release $(88.25 \%)$ in alcoholic buffer than in SIF and SGF. Consequently, it is also vital to explore the inclusion of alcohol in the formulation as it was observed to improve the solubility and consequently the dissolution of artemether. By implication, incorporation of alcohol in the formulation would be a practical approach to improve artemether bioavailability from the SLM. Overall, formulation of artemether-loaded SLM using compritol $888{ }^{\circledR}$ ATO and goat fat-based lipid matrices could be employed as a new delivery tool for the oral administration of artemether.

\section{ACKNOWLEDGEMENTS}

The authors thank Phospholipid GmbH, Koln, Germany, and Gattefossé, USA for the generous gift of Phospholipon ${ }^{\circledR}$ 90G and Compritol $888^{\circledR}$ ATO, respectively, used in the study. We also wish to thank JUHEL Pharmaceutical limited Enugu, Nigeria for gift of pure artemether sample.

\section{CONFLICT OF INTEREST}

The authors do not have any conflict of interest in the preparation of this manuscript and they received no funding for the research work.

\section{REFERENCES}

1. WHO world malaria report. 2019. Regional and global trends in burden of malaria cases and deaths. http://www.who.int

2. Santos-Magalhaes, N.S. and Mosqueira, V.C.F. 2010. Nanotechnology applied to the treatment of malaria. $A d v$. Drug Deliv. Rev. 62, 560-575.

3. Obonyo, C.O., Juma, E.A., Ogutu, B.R., Vulude, J.M. and Lau, J. 2007. Amodiaquine combined with sulphadoxine/pyrimethamine versus artemisinin-based combinations for the treatment of uncomplicated falciparum malaria in Africa: a meta-analysis. Trans. Roy. Trop. Med. Hyg. 101, 117-126.

4. Agbo, C.P., Umeyor, C.E., Kenechukwu, F.C., Ogbonna, J.D.N., Chime, S.A., Charles, L., Agubata, O., Ofokansi, K.C. and Attama, A.A. 2016. Formulation design, in vitro characterizations and anti-malarial investigations of artemether and lumefantrine-entrapped solid lipid microparticles. Drug Dev. Ind. Pharm. 42, 1708-1721.

5. Eradel, M.S., Gungor, S., Ozsoy, Y. and Araman, A. 2009. Preparation and in vitro evaluation of indomethacin loaded solid lipid microparticles. Acta Pharma Sci. 51, 203-210.

6. Jaspart, S., Piel, G., Delattre, L. and Evrard, B. 2005. Solid lipid microparticles: formulation, preparation, characterization, drug release and applications. Expert Opin. Drug Deliv. 2, 75-87.

7. Umeyor, C.E., Kenechukwu, F.C., Uronnachi, E.M. and Osonwa, U. 2012. Solid lipid microparticles (SLMs): an effective lipid-based technology for controlled drug delivery. Am. J. PharmTech Res. 2, 1-18.

8. Mishra, P., Agrawal, S. and Gupta, D. 2012. Solid lipid microparticles gel loaded with herbal extracts for acne treatment. J. Pharm. Res. 5, 104-107.

9. Ranjha, N.M., Khan, H. and Naseem, S. 2010. Encapsulation and characterization of controlled release flurbiprofen-loaded microsphere using beeswax as an encapsulating agent. $J$. Mater. Sci. Mater. Med. 21, 162-1630. 
10. Milak, S., Medicott, N. and Tucker, I.G. 2006. Solid lipid microparticles containing loratidine prepared using a micromixer. J. Microencapsul. 23, 823-831.

11. Ogbonna, J.D.N., Nzekwe, I.T., Kenechukwu, F.C., Nwobi, C.S., Amah, J.I. and Attama, A.A. 2015. Development and evaluation of chloroquine phosphate microparticles using solid lipid as a delivery carrier. J. Drug Discov. Dev. Deliv. 2, 1011-1019.

12. Ogbonna, J.D.N., Kenechukwu, F.C., Nwobi, C.S., Chibueze, O.S. and Attama, A.A. 2014. Formulation, in vitro and in vivo evaluation of halofantrine-loaded solid lipid microparticles. Pharm. Dev. Technol. 20, 941-948.

13. Kenechukwu, F.C., Umeyor, C.E., Momoh, M.A., Ogbonna, J.D.N., Chime, S.A., Nnamani, P.O. and Attama, A.A. 2014. Evaluation of gentamicin-entrapped solid lipid microparticles formulated with a biodegradable homolipid from Capra hircus. Trop. J. Pharm. Res. 13, 1199-1205.

14. Lewis, S.A., Wadhwa, A., Mathura, V., Rathnanand, M. and Naha, A. 2019. Compritol ${ }^{\circledR} 888$ ATO lipid matrix via screw extruder. Int. J. App. Pharm. 11, 261-264.

15. Aburhama, M.H. and Badr-Eldin, S.M. 2014. Compritol ${ }^{\circledR}$ 888 ATO: a multifunctional lipid excipient in drug delivery systems and nanopharmaceuticals. Exp. Opin. Drug Deliv. 11, 1865-1883.

16. Khatri, H., Chokshi, N., Rawal, S. and Patel, M.M. 2019. Fabrication, characterization and optimization of artemether loaded PEGylated solid lipid nanoparticles for the treatment of lung cancer. Mater. Res. Express. https://doi.org/10.1088/2053-1591/aaf8a3

17. Attama, A.A., Nzekwe, I.T., Nnamani, P.O., Adikwu, M.U. and Onugu, C.O. 2003. The use of solid self-emulsifying systems in the delivery of diclofenac. Int J Pharm. 262, 2328.

18. Schneeweis, A. and Muller-Goymann, C.C. 2000. Controlled release of solid-reversed micellar- solution (SRMS) suppositories containing metoclopramide HCl. Int. J. Pharm. 196, 193-196.

19. Attama, A.A., Schike, B.C. and Muller-Goymann, C.C. 2006. Further characterization of theobroma oil-beeswax admixtures as lipid matrices for improved drug delivery systems. Eur. J. Pharm. Biopharm. 64, 294-306.

20. Nnnamani, P.O., Attama, A.A., Ibezim, E.C. and Adikwu, M.U. 2010. SRMS142-based SLM: application in oral delivery of glibenclamide to diabetic rats. Eur. J. Pharm. Biopharm. 76, 68-74.

21. Attama, A.A. and Muller-Goymann, C.C. 2006. A critical study of novel physically structured lipid matrices composed of a homolipid from Capra hircus and theobroma oil. Int. J. Pharm. 322, 67-78.

22. Nnamani, P.O., Ibezim, E.C., Attama, A.A. and Adiukwu, M.U. 2010. Surface modified solid lipid microparticles based on homolipids and $\operatorname{softisan}^{\circledR}$ 142: preliminary characterization. Asian Pac. J. Trop. Med. 205-210.
24. Attama, A.A., Schike, B.C., Paepenmuller, T. and MullerGoymann, C.C. 2007. Solid lipid nanodispersions containing mixed lipid core and a polar heterolipid: characterization. Eur. J. Pharm. Biopharm. 64, 48-57.

25. Schubert, M.A., Schike, B.C. and Muller-Goymann, C.C. 2005. Thermal analysis of the crystallization and behavior of lipid matrices and lipid nanoparticles containing high amounts of lecithin. Int. J. Pharm. 298, 242-254.

26. Schubert, M.A. and Muller-Goymann, C.C. 2005. Characterization of surface-modified solid lipid nanoparticles (SLN): influence of lecithin and non-ionic emulsifier. Eur. $J$. Pharm. Biopharm. 61, 77-86.

27. Kenechukwu, F.C., Umeyor, C.E., Ogbonna, J.D.N., Builders, P.F. and Attama, A.A. 2011. Preliminary study on the functional properties of gentamicin in SRMS-based solid lipid microparticles. Int. J. Novel Drug Deliv. Tech. 2, 130142.

28. Attama, A.A., Schike, B.C. and Muller-Goymann, C.C. 2006. Further characterization of theobroma oil -beeswax admixtures as lipid matrices for improved drug delivery systems. Eur. J. Pharm. Biopharm. 64, 294-306.

29. Umeyor, C.E., Kenechukwu, F.C., Ogbonna, J.D.N., Chime, S.A. and Attama, A.A. 2012. Preparation of novel solid lipid microparticles loaded with gentamicin and its evaluation in vitro and in vivo. J. Microencapsul. 29, 296-308

30. Nogueira, B., Perdiz-Senna, J., Ricci, J.E. and Mansur, C. 2016. Polymer-based drug delivery systems applied to insect repellents devices: a review. Curr. Drug Deliv. 13, 414-426.

31. Bamigbola, E.A., Attama, A.A. and Ogeh, P.C. 2018. Evaluation of physico-mechanical and mucoadhesive properties of biopolymer films from Cola acuminata gum. Nig. J. Pharm. Res. 14, 1-13.

32. Nahla, S.B. and Alaa-Eldeen, B.Y. 2006. In vitro characterization of carbamazepine-loaded precifac lipospheres. Drug Deliv. 13, 95-104.

33. Gupta, A.K., Garg, S.K., Pal, S.K., Saxena, M. and Sharma, A. 2011. Development and characterization of SRMS microspheres of repaglinide. J. Drug Deliv. Therapeut. 1, 71-77.

34. Momoh, M.A., Adedokun, M.O. and Muazu, J. 2016. Evaluation of novel solid lipid drug delivery system: oral delivery of a herbal antidiabetic extract. British J. Pharm. Res. 13, 1-10.

35. Dash, S., Murthy, P.N., Nath, L. and Chowdhury, P. 2010. Kinetic modelling on drug release from controlled drug delivery systems. Acta Polon Pharmaceut. Drug Res. 67, 217-23.

36. Freitas, M.N. and Marchetti, J.M. 2005. Nimesulide PLA microspheres as a potential sustained release system for the treatment of inflammatory diseases. Int. J. Pharm. 295, 201-211. 